\title{
Combining ability, floral biology, and seed producibility of promising cytoplasmic male-sterile (CMS) lines for hybrid rice development
}

Victoriano V. Casco ${ }^{1 *} \mathbb{D}$, Rosemarie T. Tapic ${ }^{2}$, Jerwin R. Undan², Anna Ma. Lourdes S. Latonio², Roel R. Suralta ${ }^{3}$ and Norvie L. Manigbas ${ }^{3}$

\begin{abstract}
Background: A combining ability analysis is a useful tool of plant breeders in screening and identifying promising parental lines with high potential for developing competitive rice hybrids. Also, one important factor that strongly determines the suitability of commercial utilization of hybrid rice parental lines is their extent of seed producibility.

Methods: In this study, the combining ability, floral biology and seed producibility of cytoplasmic male sterile (CMS) lines were investigated to identify good combiners with good seed production potential. The Line $\times$ Tester analysis was used to determine the general combining abilities (GCA) of hybrid rice parental lines, and Specific Combining Abilities (SCA) of the different hybrid combinations. A correlation analysis was also done to determine floral traits that influence the outcrossing rate of the CMS lines. There were 4 CMS lines, 6 restorer lines, 24 hybrid combinations and 1 check variety in a randomized complete block Design (RCBD) with 3 replicates.
\end{abstract}

Results: Results indicated that CMS lines IR79128B and IR102758B were good combiners and the most promising restorer lines were D2031-7-1-2R, Hanareumbyeo 2, and XTR036-54-10R. Based on specific combining ability test, the most promising combination was entry 10 (IR58025A/D2013-7-1-2R). It has the highest yield of $7496 \mathrm{~kg} \mathrm{ha}^{-1}$, a high positive SCA score of 570.54, and highest standard heterosis of 12.9\%. Based on floral traits, IR79128B was the most promising with a high positive GCA score of 186.93 , panicle exertion rate of $74.8 \%$, and a high outcrossing rate of $51 \%$. There was a significant positive association between outcrossing rate, duration of floral opening, panicle exertion rate, and general combining ability.

Conclusion: The floral traits found to be significantly associated with outcrossing rate are useful selection criteria not only for identifying economically usable CMS lines but also for developing new and promising parental lines and hybrids. These CMS lines do not only give heterotic combinations but are also commercially producible, the two most important factors to the success of any hybrid rice breeding program.

Keywords: Combining ability, Floral traits, Hybrid rice, Heterosis

${ }^{*}$ Correspondence: vvcasco1909@gmail.com

${ }^{1}$ Isabela State University, Echague, Isabela, Philippines

Full list of author information is available at the end of the article

\section{Background}

According to the Food and Agriculture Organization (FAO) of the United Nations, there are more than 150 million hectares of rice fields worldwide (Ricepedia.org. 2018). Irrigated lowland fields make up over half of this 
area and produce $75 \%$ of the world's rice. These remain the most important rice production systems for food security-especially in Asian countries.

Hybrid Rice Technology is one of the viable options developed and exploited in many countries to help increase rice production. Hybrid rice could yield 15-20\% higher than the best conventional inbred rice varieties under similar conditions (Virmani 1996).In China, about half, or approximately 15 million hectares are planted to hybrid rice and because of this technology, average yield per hectare had increased from 3.5 to 6.2 tha $^{-1}$ (FAO 2014). Grown on about 1 million ha in 2003 in Asia, several hybrids from the public and private sectors have been released and commercialized in India, the Philippines, Vietnam, Bangladesh, and Indonesia. Farmers are harvesting 1-1.5 tha ${ }^{-1}$ higher yield from these hybrids (Virmani and Kumar 2004).

Hybrid rice development requires rigid evaluation and selection of parental lines before they are effectively utilized in order to develop high yielding hybrids. Parental lines must have good combining ability as well as exhibit heterotic combinations, among other traits. Hence, they should be thoroughly tested for combining ability, heterosis, and seed producibility. A high yielding hybrid should also be economically producible. If seed yield is low, cost of production may be too high and consequently the price of $F_{1}$ seeds would be too expensive that many famers cannot afford. Hence, seed producibility of any hybrid is a necessary requirement of hybrid rice development efforts. Therefore, while emphasis on yield is important in any hybrid rice breeding program, the seed production potential of any hybrid combination should first be considered before attempting to deploy a particular hybrid for commercial cultivation.

\section{Methods \\ Combining ability test}

The study is composed of 4 CMS lines, 6 restorer lines, and 24 hybrid combinations. The corresponding maintainer lines (B lines) were used instead of the A lines in order to harvest seeds needed for yield performance determination. A standard check, NSIC Rc 222, was used for standard heterosis. The complete list of entries is shown in Table 1.

\section{Cultural management}

Prior to land preparation, first plowing was done 3 weeks before transplanting followed by two harrowing on a week interval. Final leveling was done one day before transplanting. The wet seedbed method was used to raise seedlings. A seeding rate of $50 \mathrm{~g}$ per square meter of seedbed was used. Complete fertilizer (14-14-14) was applied 10 days after seeding at $10 \mathrm{~g}$ per square meter of seedbed. Transplanting was done 21 days after seeding at 1-2 seedlings per hill in a spacing of $20 \times 20 \mathrm{~cm}$. Replanting of missing hills was done at 5 days after transplanting. Pre-emergence herbicide was

Table 1 List of test entries

\begin{tabular}{|c|c|c|c|}
\hline Entry no & Parentage & Entry no & Parentage \\
\hline A. Crosses & & 20 & IR79128A/Hanareumbyeo 2 \\
\hline 1 & IR58025A/XTR036-54-10R & 21 & IR58025A/IR49689-84-2-1-2R \\
\hline 2 & IR93560A/XTR036-54-10R & 22 & IR102758A/IR49689-84-2-1-2R \\
\hline 3 & IR79128A/XTR036-54-10R & 23 & IR93560A/IR49689-84-2-1-2R \\
\hline 4 & IR102758A/XTR036-54-10R & 24 & IR79128A/IR49689-84-2-1-2R \\
\hline 5 & IR19128A/Taebaegbyeo & B. CMS Lines & \\
\hline 6 & IR58025A/Tabaegbyeo & 25 & IR102758B \\
\hline 7 & IR93560A/Taebaegbyeo & 26 & IR58025B \\
\hline 8 & IR102758A/Taebaegbyeo & 27 & IR79128B \\
\hline 9 & IR102758A/D2031-7-1-2R & 28 & IR93560B \\
\hline 10 & IR58025A/D2031-7-1-2R & C. Restorer Lines & \\
\hline 11 & IR79128A/D2031-7-1-2R & 29 & D2031-7-1-2R \\
\hline 12 & IR93560A/D2031-7-1-2R & 30 & IR 49689-84-2-1-2R \\
\hline 13 & IR102758A/XTR023-23-1-2-1-1R & 31 & Taebaegbyeo \\
\hline 14 & IR58025A/XTR023-23-1-2-1-1R & 32 & XTR023-23-1-2-1-1R \\
\hline 15 & IR93560A/XTR023-1-2-1-1R & 33 & Hanareumbyeo 2 \\
\hline 16 & IR79128A/XTRO23-23-1-2-1-1R & 34 & XTR036-54-10R \\
\hline 17 & IR93560A/Hanareumbyeo 2 & D. Check Variety & \\
\hline 18 & IR102758A/Hanareumbyeo 2 & 35 & NSIC Rc 222 \\
\hline 19 & IR58025A/Hanareumbyeo 2 & & \\
\hline
\end{tabular}


applied 3 days after transplanting while molluscicide was applied immediately after transplanting. The study was fully protected against pests and diseases to avoid damage on plants. Intermittent irrigation was practiced to allow soil aeration as well as better root and tiller development. However, 5-7 cm of water was maintained during the reproductive stage to ensure sufficient moisture required for grain development.

Harvesting was done when $85 \%$ of the grains in the panicle have turned into golden yellow color. Four inner rows of each plot per replication were harvested. Samples were cleaned immediately after harvesting and dried to $14 \%$ moisture content before weighing.

\section{Data gathered}

The following data were gathered accordingly based on the procedures outlined in the standard evaluation system (SES) for rice (SES 5th Edition, IRRI. 2013).

- Days to $50 \%$ flowering-the number of days from seeding to $50 \%$ of the plants in a plot have emerged panicles.

- Number of productive tillers per plant-the average number of panicle bearing tillers per hill from the five randomly selected plants at the center row of the plot.

- Filled grains per panicle-the average number of filled grains per panicle taken from five randomly selected panicles from five randomly selected plants at the center row of the plot.

- Number of spikelets per panicle-the average number of spikelets per panicle taken from five randomly selected panicles from five randomly selected plants at the center row of the plot.

- Spikelet fertility (\%)-the ratio of filled grains and total number of spikelets per panicle multiplied by 100 .

- 1000-grain weight (g) - the weight of 1000 seeds randomly taken from the bulk harvested center row of the plot.

- Yield per hectare $(\mathrm{kg})$ - the yield in kilograms per hectare at 14\% moisture content computed from weight of the harvested center row of the plot using the following formula:

$$
\begin{aligned}
& \text { Yield per ha kg at } 14 \% \mathrm{MC} \\
& =\frac{\text { Plot Weight }(\mathrm{kg})}{\text { Plot Area }\left(\mathrm{m}^{2}\right)} \times \frac{(100-\mathrm{MC})}{86} \times 10,000
\end{aligned}
$$

\section{Data analysis}

Generation of the Analysis of Variance (ANOVA) Tables for agronomic traits was done using the statistical tool for agricultural research (STAR, v2.0.1) that was freely downloaded from the website of the Breeding and Bioinformatics Division of the International Rice Research Institute (IRRI). On the other hand, the line $x$ tester analysis was performed using the statistical analysis system (SAS v9.1.3.2).

The standard heterosis was computed to determine the yield advantage of the test hybrids over the standard check and be able to identify promising combinations.

It was computed using the following formula:

$$
\begin{aligned}
& \text { Standard Heterosis }(\%) \\
& \quad=\left(\frac{\text { Plot per ha }- \text { Yield of Check }}{\text { Yield of Check }}\right) \times 100
\end{aligned}
$$

The combining ability nursery was composed of six ' $l$ ' lines (restorers), four ' $t$ ' testers (CMS lines) crossed to each other to compose twenty-four ' $l \times t^{\prime}$ ' experimental hybrids and one standard check variety.

The estimation of the general combining ability (GCA) effect was done using the following formula:

a. $\operatorname{GCA}($ line $)=\frac{\mathrm{Yi} \ldots}{\operatorname{tr}}-\frac{\mathrm{Y} \ldots}{\mathrm{ltr}}$

where Yi is the total of ith line over testers; Y.. is the Grand Total; $l$ is the Number of lines; $t$ is the Number of tester; $r$ is the Number of replications.

The sum of individual GCA of lines should equal to zero:

$\sum \mathrm{GCA}($ line $)=0$

b. $\quad$ GCA $($ tester $)=\frac{\sum Y . j .}{\operatorname{lr}}-\frac{Y . .}{\operatorname{ltr}}$

where Y.j. is the total of jth tester over lines; Y.. is the Grand Total; l,t,r is the lines, testers and replication, respectively.

The sum of individual GCA of lines should equal to zero:

$$
\sum \mathrm{GCA}(\text { tester })=0
$$

The estimation of the Specific Combining Ability (SCA) effect was done using the following formula:

$$
\mathrm{Sij}=\frac{\text { Yij. }}{\mathrm{r}}-\frac{\text { Yi.. }}{\mathrm{rt}}-\frac{\mathrm{Y.j} .}{\mathrm{rl}}-\frac{\mathrm{Y.} .}{\mathrm{ltr}}
$$

where Yij. is the Value of jth line with ith tester; Yi.. is the Total of ith line over all testers; Y.j. is the Total of jth tester over all lines; Y.. is the Grand Total; l,t,r is the Number of lines, testers, and replications, respectively.

Note: SCA effects for all hybrids should be equal to zero: 


$$
\sum_{I} \sum_{j} S_{i j}=0
$$

\section{Floral characteristics and seed producibility of CMS lines}

The seed producibility test was conducted on CMS lines by evaluating their floral traits that contribute to a good seedset.

The following data were gathered:

- Panicle exertion rate (\%)-is the ratio of the portion of the panicle exerted out of the leaf sheath to the total length of the panicle multiplied by 100 . This is an average of five randomly selected panicles from 5 randomly selected plants in the center row of the plot.

- Duration of floral opening (minutes) - is the average duration of floral opening taken from 10 randomly selected unopened spikelets in one panicle. It was conducted in the field but for purposes of convenience. The test plants were transferred to plastic pails one day before evaluation. The time of floral opening and closing were recorded and the duration in minutes was determined.

- Duration of stigma receptivity (days) - is the period of time in number of days that the stigma is receptive to pollen grains. Stigma receptivity is assessed in terms of the number of seeds produced in a panicle after hand pollination. It was be taken as follows:

a. One hundred (100) spikelets from each of seven randomly selected panicles were clipped in one day and bagged.

b. The following day and each day thereafter, one panicle was pollinated. Since there were seven panicles each composed of 100 clipped spikelets, it took seven successive days to completely pollinate all the sampled panicles.

c. Counting of pollinated seeds was done 7 days after pollination. d. As a minimum standard, the duration of stigma receptivity was based on 30\% seed set. Any seed set less than this was discarded. Hence, the duration of stigma receptivity is the period at which at least 30\% seed set was attained in each of the panicles pollinated each day.

- Outcrossing rate (\%)-is the ratio of the number of pollinated seed-bearing spikelets and the total number of spikelets in one panicle multiplied by 100. It is the average percent seed set per panicle. Data on outcrossing rate were taken from the stigma receptivity test. It is the average seed set percentage during the 7 days of successive pollination

\section{Results and discussion \\ Combining ability test}

For agronomic traits, there were highly significant variability among the entries (Table 2). The hybrids performed better than the parent lines in number of spikelets per panicle, filled grains pare panicle, 1000-grain weight and yield per hectare (Table 3). Hybrids were also taller than the parents but showed similar maturity and number of productive tillers. For plant height, negative GCA effects are more desirable as shorter plant height is advantageous to avoid lodging (Rashid et al. 2007). The restorer lines had higher average spikelet fertility compared with both the hybrid combinations and the CMS lines. These results were similar with previous findings by Gramaje et al (2020), Azmath et al (2018), and Rashid et al (2007).

The ANOVA for the combining ability test (Table 4) showed highly significant variances among parents and hybrids. Partitioning of parental variances into lines and testers revealed that there were also highly significant variances due to lines except for spikelet fertility, weight of 1000 grains, and yield while due to testers, only total number of spikelets per panicle showed significant differences. The line $\mathrm{x}$ tester interaction was significant for maturity, spikelet fertility, weight of 1000 grains, and yield. Highly significant line $\mathrm{x}$ tester

Table 2 Error and mean sum of squares for agronomic traits

\begin{tabular}{|c|c|c|c|c|c|c|c|c|c|}
\hline $\begin{array}{l}\text { Source of } \\
\text { variation }\end{array}$ & df & $\begin{array}{l}\text { Plant height } \\
\text { (cm) }\end{array}$ & Tillers per hill & Maturity & $\begin{array}{l}\text { Total No of } \\
\text { spikelets }\end{array}$ & Filled grains & $\begin{array}{l}\text { Spikelet fertility } \\
(\%)\end{array}$ & $\begin{array}{l}\text { Weight of } \\
1000 \text { grains } \\
\text { (g) }\end{array}$ & Yield per ha $(\mathbf{k g})$ \\
\hline Rep & 2 & $137.40^{*}$ & 2.60 & $9.80^{* *}$ & 685.55 & 497.15 & 48.28 & 7.94 & $392,764.30$ \\
\hline Entry & 34 & $218.58^{* *}$ & $8.82^{* *}$ & $122.94^{* *}$ & $1647.77^{* *}$ & $1065.37^{* *}$ & $186.34^{* *}$ & $10.78^{* *}$ & $2,672,806.99^{* *}$ \\
\hline Error & 68 & 36.96 & 2.52 & 1.97 & 554.03 & 467.10 & 31.33 & 3.89 & $1,067,020.50$ \\
\hline
\end{tabular}

" Significant at 5\%

${ }^{* *}$ Significant at $1 \%$ 
Table 3 Summary of agronomic performance of lines, testers, hybrids, and check variety

\begin{tabular}{|c|c|c|c|c|c|c|c|c|c|c|}
\hline Entry no & Parent/hybrid & $\mathrm{PhA}$ & $\mathrm{PH}$ & MAT & TLR & SPK & SPF & FG & GW & YLD \\
\hline 1 & IR58025A/XTR036-54-10R & 4 & 133 & 117 & 12 & 188 & 62.7 & 118 & 23.0 & 6346 \\
\hline 2 & IR93560A/XTR036-54-10R & 6 & 138 & 123 & 14 & 206 & 66.2 & 136 & 25.5 & 5538 \\
\hline 3 & IR79128A/XTR036-54-10R & 3 & 129 & 121 & 15 & 163 & 77.3 & 126 & 23.8 & 7203 \\
\hline 4 & IR102758A/XTR036-54-10R & 3 & 131 & 115 & 13 & 181 & 69.3 & 127 & 25.0 & 6752 \\
\hline 5 & IR79128A/Taebaegbyeo & 6 & 123 & 105 & 11 & 175 & 78.7 & 137 & 23.9 & 7122 \\
\hline 6 & IR58025A/Tabaegbyeo & 6 & 127 & 107 & 12 & 215 & 72.8 & 157 & 24.9 & 5895 \\
\hline 7 & IR93560A/Taebaegbyeo & 6 & 125 & 103 & 10 & 216 & 65.3 & 141 & 24.6 & 6502 \\
\hline 8 & IR102758A/Taebaegbyeo & 6 & 117 & 106 & 11 & 192 & 68.2 & 132 & 23.1 & 5862 \\
\hline 9 & IR102758A/D2031-7-1-2R & 4 & 125 & 104 & 11 & 195 & 80.5 & 157 & 24.2 & 7150 \\
\hline 10 & IR58025A/D2031-7-1-2R & 5 & 128 & 106 & 12 & 209 & 72.2 & 154 & 21.7 & 7496 \\
\hline 11 & IR79128A/D2031-7-1-2R & 5 & 130 & 104 & 12 & 173 & 81.1 & 142 & 23.9 & 6524 \\
\hline 12 & IR93560A/D2031-7-1-2R & 6 & 122 & 104 & 12 & 189 & 87.5 & 166 & 22.1 & 6133 \\
\hline 13 & IR102758A/XTR023-23-1-2-1-1R & 3 & 124 & 101 & 10 & 206 & 78.4 & 162 & 23.1 & 6702 \\
\hline 14 & IR58025A/XTR023-23-1-2-1-1R & 4 & 127 & 106 & 9 & 210 & 67.8 & 144 & 21.4 & 5958 \\
\hline 15 & IR93560A/XTR023-1-2-1-1R & 6 & 128 & 109 & 11 & 200 & 78.2 & 155 & 22.9 & 5428 \\
\hline 16 & IR79128A/XTRO23-23-1-2-1-1R & 4 & 134 & 105 & 11 & 180 & 73.4 & 134 & 22.6 & 5850 \\
\hline 17 & IR93560A/Hanareumbyeo 2 & 3 & 130 & 121 & 12 & 224 & 76.1 & 171 & 22.9 & 7052 \\
\hline 18 & IR102758A/Hanareumbyeo 2 & 4 & 124 & 111 & 14 & 219 & 69.7 & 153 & 22.4 & 6828 \\
\hline 19 & IR58025A/Hanareumbyeo 2 & 4 & 123 & 109 & 12 & 230 & 75.2 & 173 & 24.3 & 6563 \\
\hline 20 & IR79128A/Hanareumbyeo 2 & 5 & 134 & 108 & 11 & 200 & 65.5 & 131 & 28.7 & 6811 \\
\hline 21 & IR58025A/IR49689-84-2-1-2R & 5 & 122 & 104 & 12 & 159 & 80.4 & 126 & 24.0 & 6574 \\
\hline 22 & IR102758A/IR49689-84-2-1-2R & 5 & 122 & 104 & 12 & 152 & 73.1 & 111 & 27.0 & 5595 \\
\hline 23 & IR93560A/IR49689-84-2-1-2R & 5 & 120 & 102 & 10 & 166 & 67.4 & 111 & 26.8 & 6412 \\
\hline \multirow[t]{2}{*}{24} & IR79128A/IR49689-84-2-1-2R & 5 & 119 & 105 & 14 & 166 & 72.3 & 119 & 24.0 & 6248 \\
\hline & Mean of crosses & & 126 & 108 & 12 & 192 & 73 & 141 & 24 & 6439 \\
\hline 25 & IR102758B & 6 & 114 & 114 & 14 & 155 & 71.1 & 109 & 21.4 & 4018 \\
\hline 26 & IR58025B & 5 & 109 & 113 & 14 & 206 & 67.5 & 139 & 19.6 & 3704 \\
\hline 27 & IR79128B & 3 & 132 & 113 & 9 & 188 & 89.7 & 169 & 23.7 & 7253 \\
\hline \multirow[t]{2}{*}{28} & IR93560B & 5 & 99 & 93 & 11 & 164 & 68.3 & 111 & 19.1 & 3852 \\
\hline & Mean of testers & & 113 & 108 & 12 & 178 & 74 & 132 & 21 & 4707 \\
\hline 29 & D2031-7-1-2R & 6 & 139 & 114 & 13 & 173 & 86.0 & 149 & 23.0 & 5471 \\
\hline 30 & IR 49689-84-2-1-2R & 5 & 115 & 107 & 10 & 142 & 91.9 & 130 & 22.3 & 5328 \\
\hline 31 & Taebaegbyeo & 4 & 110 & 104 & 13 & 153 & 89.8 & 138 & 22.8 & 5608 \\
\hline 32 & XTR023-23-1-2-1-1R & 3 & 115 & 104 & 9 & 194 & 82.6 & 160 & 21.9 & 5403 \\
\hline 33 & Hanareumbyeo 2 & 5 & 117 & 110 & 13 & 191 & 78.2 & 149 & 23.6 & 5021 \\
\hline \multirow[t]{2}{*}{34} & XTR036-54-10R & 4 & 121 & 117 & 17 & 154 & 70.1 & 108 & 23.9 & 6758 \\
\hline & Mean of lines & & 119 & 109 & 12 & 168 & 83 & 139 & 23 & 5598 \\
\hline \multirow[t]{4}{*}{35} & NSIC Rc 222-check & 4 & 124 & 114 & 14 & 203 & 64.6 & 132 & 21.5 & 6657 \\
\hline & Grand mean & & 124 & 109 & 12 & 187 & 74.8 & 139 & 23 & 6103 \\
\hline & LSD & & 19.84 & 4.58 & 5.18 & 76.8 & 18.27 & 70.54 & 6.44 & 3372 \\
\hline & CV (\%) & & 4.92 & 1.29 & 13.11 & 12.60 & 7.48 & 15.51 & 8.44 & 16.92 \\
\hline
\end{tabular}

PhA Phenotypic acceptability, PH Plant height (cm), MAT Maturity (DAS), TLR Number of productive tillers, SPKTotal number of spikelets, SPF Spikelet fertility (\%), FG Number of filled grains per panicle, GW 1000-grain weight (g)

interactions were also observed in past studies conducted by Alam et al. (2007), Yadav et al.(1999), and Perraju and Sharma (1999)

Based on GCA scores, the good combiners for yield among CMS lines were IR79128B and IR102758B while among restorer lines they were D2031-7-1-2R and Hanareumbyeo 2 (Table 5). Other parental lines also showed positive GCA effects for some yield components. Results of previous studies also showed some CMS lines to be good general combiners for yield 
Table 4 Analysis of variance for general combining ability of lines, testers and hybrids

\begin{tabular}{|c|c|c|c|c|c|c|c|c|}
\hline Source of variation & Plant height & Productive tillers & Maturity & $\begin{array}{l}\text { Total } \\
\text { number of } \\
\text { spikelets }\end{array}$ & Spikelet fertility & Filled grains & $\begin{array}{l}\text { Weight } \\
\text { of } 1000 \\
\text { grains }\end{array}$ & Yield \\
\hline Replication & $137.40^{*}$ & 2.60 & $9.80^{*}$ & 685.55 & 48.28 & 497.15 & 7.94 & $392,764.30$ \\
\hline Entry & $218.58^{* *}$ & $8.82^{* *}$ & $122.94^{* *}$ & $1647.77^{* *}$ & $186.34^{* *}$ & $1065.37^{* *}$ & $10.78^{* *}$ & $2,672,806.99 * *$ \\
\hline Check vs $(\mathrm{P}, \mathrm{H})$ & 0.15 & $15.21^{*}$ & $79.28^{* *}$ & 775.60 & $323.22^{* *}$ & 166.94 & 10.56 & $946,786.29$ \\
\hline PVSH & $1893.34^{* *}$ & 2.01 & 7.34 & $8796.01^{* *}$ & $821.04^{* *}$ & 521.21 & $73.74^{* *}$ & $30,369,022.67^{* *}$ \\
\hline Parent (P) & $399.76^{* *}$ & $16.21^{* *}$ & $153.57^{* *}$ & $1406.03^{*}$ & $282.24 * *$ & $1389.10^{* *}$ & $8.28^{*}$ & $4,135,942.40^{* *}$ \\
\hline Hybrid (H) & $84.37^{* *}$ & $5.95^{* *}$ & $117.87^{* *}$ & $1469.49^{*}$ & $115.26^{* *}$ & $1001.42^{* *}$ & $9.03^{* *}$ & $971,136.83$ \\
\hline Line & $216.75^{* *}$ & $14.63^{*}$ & $430.06^{* *}$ & $4401.51^{* *}$ & 186.31 & $3070.39^{* *}$ & 14.23 & $1,342,706.35$ \\
\hline Tester & 57.85 & 4.01 & 31.59 & $2256.98^{* *}$ & 25.13 & 876.17 & 2.71 & $684,064.35$ \\
\hline Line $\times$ tester & 45.54 & 3.45 & $31.07^{* *}$ & 334.65 & $109.61^{* *}$ & 336.81 & $8.56^{*}$ & $904,694.81$ \\
\hline Error & 36.96 & 2.52 & 1.97 & 554.03 & 31.33 & 467.10 & 3.89 & $1,067,020.50$ \\
\hline
\end{tabular}

*Significant at 5\%

**Significant at $1 \%$

and yield components (Anand et al. 1999, Yadav et al. 1999). Some parents showed negative GCA effects for plant height and maturity, indicating that they can be utilized in developing hybrid rice with early maturity and short plant stature (Rashid et al. 2007). Choosing parents with high GCA effects for hybridization is one way of increasing chances of developing promising rice hybrids as well as attainment of efficiency in terms of reduced cost, effort and time in handling a large number breeding materials. Also, crosses involving parents with high GCA score generally result into hybrids with high SCA scores (Azmath et al. 2018), and high per se performance.

\section{Floral biology and seed producibility}

Evaluating the floral biology and seed producibility will identify CMS lines with good producibility for possible utilization in commercial hybrid rice seed production, and determine specific floral traits responsible for high producibility of CMS lines which can be used as basis in breeding for promising and commercially producible hybrid rice cultivars.

\section{Duration of stigma receptivity}

The duration of stigma receptivity did not vary among the four CMS lines (Table 6). The best CMS lines for this trait are IR102758A and IR93560A as they are still receptive to pollen at 7 days after floral opening.

The duration of stigma receptivity is the number of days that the stigma stays receptive as shown by its ability to get pollinated after floral opening. This floral trait is regarded as very important; that is, the longer the duration, the higher chance it is for the stigma to be pollinated assuming that there is also unhampered availability

Table 5 Estimate of general combining ability of lines, testers and crosses

\begin{tabular}{llllccccrr}
\hline & Parents & PH & MAT & TLR & SPK & SPF & FG & GW & YLD \\
\hline Testers & & & & & & & & & \\
25 & IR102758B & -2.39 & $-1.17^{*}$ & 0.32 & 0.76 & -1.48 & -1.14 & -0.28 & 99.71 \\
26 & IR58025B & -0.28 & -0.56 & -0.46 & $7.32^{*}$ & -0.08 & 4.86 & -0.35 & -24.90 \\
27 & IR79128B & 1.72 & -0.17 & $0.49^{*}$ & -16.07 & 1.41 & -9.42 & $0.49^{* *}$ & 186.93 \\
28 & IR93560B & 0.94 & 1.89 & -0.35 & $7.99^{* *}$ & 0.15 & $5.69^{*}$ & 0.14 & -261.74 \\
Lines & & & & & & & & \\
29 & D2031-7-1-2R & -0.06 & $-3.86^{*}$ & 0.04 & -0.51 & $7.04^{*}$ & $13.89^{*}$ & -1.03 & 386.51 \\
30 & IR 49689-84-2-1-2R & $-5.76^{*}$ & $-4.53^{* *}$ & 0.13 & $-31.68^{*}$ & -0.01 & -24.03 & $1.46^{* *}$ & -232.15 \\
31 & Taebaegbyeo & -3.39 & $-3.03^{*}$ & -0.71 & 7.15 & -2.08 & 0.72 & 0.15 & -94.24 \\
32 & XTR023-23-1-2-1-1R & 1.74 & $-3.03^{* *}$ & $-1.63^{* *}$ & 6.90 & 1.16 & 7.72 & -1.50 & -454.82 \\
33 & Hanareumbyeo 2 & $1.03^{*}$ & $3.97^{*}$ & 0.54 & 25.90 & -1.70 & 15.81 & 0.61 & 374.18 \\
34 & XTR036-54-10R & $6.44^{* *}$ & $10.47^{* *}$ & $1.63^{*}$ & $-7.76^{*}$ & $-4.42^{*}$ & $-14.11^{*}$ & 0.31 & 20.51 \\
\hline
\end{tabular}

\footnotetext{
Significant at 5\%
}

** Significant at $1 \%$ 
Table 6 Error and mean squares for floral traits

\begin{tabular}{lclcccc}
\hline Source of Variation & df & DSR & DFO & PEX & Mean OCR & Cummulative OCR \\
\hline Replication & 6 & 0 & 310.29 & 46.82 & $996^{* *}$ & $18,661.40^{* *}$ \\
Entry & 3 & 15.75 & 919.81 & $366.06^{* *}$ & $1268.33^{* *}$ & $33,345.57^{* *}$ \\
Error & 18 & 0 & 2187.59 & 46.45 & 235.33 & 1095.0714 \\
\hline
\end{tabular}

DSR Duration of stigma receptivity (min), DFO Duration of floral opening (min), PEX Panicle exertion rate (\%), OCR Outcrossing rate (\%)

* Significant at 5\%

** Significant at $1 \%$

of viable pollen from the pollen parent in a hybrid rice seed production (Gupta et al. 2014). Similarly, Singh (2012) had also cited the importance of longer duration of stigma receptivity in facilitating stigma reception of pollen grains. Shailaja and Shankar (1987) also pointed out that duration of stigma receptivity was an important floral trait that influenced out crossing. Focusing on this trait offers a good prospect of developing parental lines with high level of seed producibility.

\section{Duration of floral opening}

Singh and Sahoo (1996) indicated that the longer the duration of floral opening, the greater is the chance for a particular CMS line to get pollinated leading to higher seedset. In the same way, Abeysekera (2003) pointed out that floral opening duration strongly influences outcrossing rate in CMS lines. The four CMS lines studied showed no significant variations in the duration of floral opening (Table 6).

\section{Panicle exertion rate}

Average panicle exertion rate of the four CMS lines was 64\%, ranging from 59.6 (IR102758A) to $74.9 \%$ (IR79128A) as shown in Table 7. The four CMS lines significantly differ on this trait based on the Analysis of Variance (Table 6). However, IR102758A, IR58025A and IR93560A had similar panicle exertion rates, while IR79128A showed significantly higher panicle exertion rate against any of these CMS lines. This strongly indicated that in combination with other important floral traits, it has a high potential to be an economically useful parent line for hybrid rice development and production. This is in support to the idea that since a larger part of the panicle is exposed, there are greater chances also that more spikelets would be pollinated, hence, more F1 seeds produced (Chen et al. 2013). A good panicle exertion in CMS would expose a higher number of spikelets for out crossing (Singh 2012).

\section{Outcrossing rate}

The CMS lines showed highly significant variations in outcrossing rate (Table 6). The highest OCR was observed in IR79128A with 51\% while IR93560A showed the lowest at $20 \%$. Overall mean OCR is $33 \%$ (Table 8 ). El-Namaky (2018) also observed an OCR of 48 to $56 \%$ in some CMS lines. Although the CMS lines vary significantly in OCR, only IR79128A showed highly significant difference against each of the other CMS lines. The three CMS lines, IR102758A, IR58025A and IR93560A, had similar OCR. Hence, IR79128A stands out as the best CMS line for OCR, specifically seed producibility, a very important trait that a prospective CMS line must possess for it to be considered to be commercially usable. This line shows a high potential for commercial utilization in hybrid rice development and seed production. In China, the outcrossing rate on CMS lines also ranged 15 to $45 \%$ (Lin and Yuan 1980; Yuan 1985). On the other hand, Virmani (1994) reported that at IRRI, one CMS line (IR62829A) had outcrossing rate of 23 to $43 \%$ resulting to a seed yield of 800 to $1200 \mathrm{kgha}^{-1}$ in the Philippines.

Table 7 General combining ability and floral traits of CMS lines

\begin{tabular}{lrllllc}
\hline CMS line & GCA & DSR & DFO & PEX & Mean OCR & $\begin{array}{l}\text { Cummulative } \\
\text { OCR }\end{array}$ \\
\hline Entry 25 (IR102758A) & 99.71 & 7 & 184 & 59.6 & 33 & 145 \\
Entry 26 (IR58025A) & -24.90 & 4 & 198 & 60.0 & 26 & 142 \\
Entry 27 (IR79128A) & 186.93 & 5 & 171 & 74.8 & 51 & 253 \\
Entry 28 (IR93560A) & -261.74 & 7 & 181 & 61.6 & 20 & 89 \\
MEAN & & 6 & 183 & 64.0 & 33 & 157 \\
\hline
\end{tabular}


Table 8 Correlation analysis among floral traits and general combining ability

\begin{tabular}{|c|c|c|c|c|c|c|}
\hline & GCA for yield & DSR & DFO & PEX & Mean OCR & $\begin{array}{l}\text { Cummulative } \\
\text { OCR }\end{array}$ \\
\hline GCA for Yield & 1 & & & & & \\
\hline DSR & -0.1357 & 1 & & & & \\
\hline DFO & -0.3057 & $-0.6553^{* *}$ & 1 & & & \\
\hline PEX & $0.5394 * *$ & 0.0652 & $-0.7961^{* *}$ & 1 & & \\
\hline Mean OCR & $0.8839 * *$ & 0.0176 & $-0.6545^{* *}$ & $0.8671^{* *}$ & 1 & \\
\hline Cummulative OCR & $0.8676^{* *}$ & -0.1712 & $-0.5445^{* *}$ & $0.8709^{* *}$ & $0.9802^{* *}$ & 1 \\
\hline
\end{tabular}

Selection of parents and hybrids based on performance, general combining ability, specific combining ability, and standard heterosis

Table 9 shows a summary of performance of hybrids including phenotypic acceptability ratings, General Combining Ability of parents, Specific Combining Ability of crosses, as well as standard heterosis. Fahasat et al. (2016) reported that parental evaluation that is based on SCA alone is not enough, but has to be used in combination with hybrid performance and high GCA of at least one of the parents. Based on these criteria, Entry 10 (IR58025A/D2031-7-1-2R) was the most promising

Table 9 Summary of performance of hybrids

\begin{tabular}{|c|c|c|c|c|c|c|c|}
\hline Entry no & Parent/hybrid & MEAN YIELD & $\mathrm{PhA}$ & GCA (female) & GCA (male) & SCA & $\begin{array}{l}\text { Standard } \\
\text { heterosis } \\
\text { (\%) }\end{array}$ \\
\hline 1 & IR58025A/XTR036-54-10R & 6346 & 4 & -24.9 & 20.51 & -88.51 & -4.67 \\
\hline 2 & IR93560A/XTR036-54-10R & 5538 & 6 & -261.74 & 20.51 & -660.35 & -16.81 \\
\hline 3 & IR79128A/XTR036-54-10R & 7203 & 3 & 186.93 & 20.51 & 556.32 & 8.20 \\
\hline 4 & IR102758A/XTR036-54-10R & 6752 & 3 & 99.71 & 20.51 & 192.54 & 1.42 \\
\hline 5 & IR19128A/Taebaegbyeo & 7122 & 6 & 186.93 & -94.24 & 589.74 & 6.98 \\
\hline 6 & IR58025A/Tabaegbyeo & 5895 & 6 & -24.90 & -94.24 & -425.10 & -11.45 \\
\hline 7 & IR93560A/Taebaegbyeo & 6502 & 6 & -261.74 & -94.24 & 418.40 & -2.33 \\
\hline 8 & IR102758A/Taebaegbyeo & 5862 & 6 & 99.71 & -94.24 & -583.04 & -11.95 \\
\hline 9 & IR102758A/D2031-7-1-2R & 7150 & 4 & -261.74 & 386.51 & 349.15 & 7.40 \\
\hline 10 & IR58025A/D2031-7-1-2R & 7496 & 5 & -24.90 & 386.51 & 570.54 & 12.60 \\
\hline 11 & IR79128A/D2031-7-1-2R & 6524 & 5 & 186.93 & 386.51 & -488.68 & -2.00 \\
\hline 12 & IR93560A/D2031-7-1-2R & 6133 & 6 & -261.74 & 386.51 & -431.01 & -7.87 \\
\hline 13 & IR102758A/XTR023-23-1-2-1-1R & 6702 & 3 & 99.71 & -454.82 & 617.88 & 0.68 \\
\hline 14 & IR58025A/XTR023-23-1-2-1-1R & 5958 & 4 & -24.90 & -454.82 & -1.51 & -10.50 \\
\hline 15 & IR93560A/XTR023-1-2-1-1R & 5428 & 6 & -261.74 & -454.82 & -294.68 & -18.46 \\
\hline 16 & IR79128A/XTRO23-23-1-2-1-1R & 5850 & 4 & 186.93 & -454.82 & -321.68 & -12.13 \\
\hline 17 & IR93560A/Hanareumbyeo 2 & 7052 & 3 & -261.74 & 374.18 & 500.65 & 5.94 \\
\hline 18 & IR102758A/Hanareumbyeo 2 & 6828 & 4 & 99.71 & 374.18 & -85.46 & 2.56 \\
\hline 19 & IR58025A/Hanareumbyeo 2 & 6563 & 4 & -24.90 & 374.18 & -225.85 & -1.41 \\
\hline 20 & IR79128A/Hanareumbyeo 2 & 6811 & 5 & 186.93 & 374.18 & -189.35 & 2.31 \\
\hline 21 & IR58025A/IR49689-84-2-1-2R & 6574 & 5 & -24.90 & -232.15 & 391.82 & -1.25 \\
\hline 22 & IR102758A/IR49689-84-2-1-2R & 5595 & 5 & 99.71 & -232.15 & -712.46 & -15.96 \\
\hline 23 & IR93560A/IR49689-84-2-1-2R & 6412 & 5 & -261.74 & -232.15 & 466.99 & -3.68 \\
\hline 24 & IR79128A/IR49689-84-2-1-2R & 6248 & 5 & 186.93 & -232.15 & -146.35 & -6.15 \\
\hline 25 & NSIC Rc 222-Check & 6657 & 4 & & & & \\
\hline
\end{tabular}


combination as it showed the highest yield among all crosses $\left(7496 \mathrm{~kg} \mathrm{ha}^{-1}\right)$, a high positive SCA of 570.54 , and the male parent (D2031-7-1-2R) showing a positive GCA of 570.4. It also exhibited a standard heterosis of $12.60 \%$ over the inbred check NSIC Rc 222. The phenotypic evaluation rating of this entry is likewise acceptable. Using the same bases for selection, the other promising entries are Entry 3 (IR79128A/XTR036-54-10R), Entry 9 (IR102758A/D2031-7-1-2R), Entry 5 (IR79128A/Taebaegbyeo), and Entry 17 (IR93560A/Hanareumbyeo 2). All of these combinations exhibited a yield performance of $7203,7150,7122$, and $7052 \mathrm{kgha}^{-1}$, respectively. They also showed a positive SCA effect, and a standard heterosis ranging from $5.94-8.2 \%$. All other entries fall below the specified performance criteria. The most promising parental lines were Entry 29 (D2031-7-1-2R), Entry 33 (Hanareumbyeo 2), Entry 34 (XTR036-54-10R), and Entry 27 (IR79128A).

\section{Combining ability and seed producibility of CMS lines}

While a parental line can be promising due to its good general combining ability and performance, its potential for commercial utilization is largely limited by its seed producibility. In other words, a parental line's ability to produce promising hybrids is not enough to consider it to be commercially usable. It must also be favorable for seed production. Hence, good general combining ability should always be considered in combination with seed producibility, which is influenced by a parent line's floral traits. A very good hybrid which is difficult to produce will have a high production cost. This will eventually result into high cost of seeds and may not be favorable to farmers and seed growers.

Table 7 shows both the GCA as well as the floral traits of CMS lines. Out of the four CMS lines, IR102758A and IR79128A had high positive GCA effects. Taking into consideration the different floral traits evaluated, IR79128A was the most promising. Aside from having high positive GCA, it had high panicle exertion rate of $74.8 \%$, and a high outcrossing rate of $51 \%$. It has an average duration of stigma receptivity (DSR) of 5 days, and an average duration of floral opening of $171 \mathrm{~min}$. The CMS line IR102758A had a DSR of 7 days, DFO of $184 \mathrm{~min}$, a panicle exertion rate of $59.6 \%$, but a lower OCR of $33 \%$. Although this CMS line had a relatively low OCR, it can still be utilized for seed production of promising hybrids since it has a good GCA effect. The remaining CMS lines had poor GCA effects as well as low OCR, and therefore cannot be suitable for developing and producing promising rice hybrids.

A correlation analysis was performed to determine the relationship among the floral traits and the GCA of CMS lines (Table 8) to identify floral traits that influence outcrossing rate or seed producibility. Results showed that both the duration of floral opening and panicle exertion rate were significantly correlated with outcrossing rate, in support to the findings of Hosain et al. (2016). This result indicates the possibility of developing and selecting parental lines with promising seed producibility by using these traits as selection criteria. The general combining ability of CMS lines was likewise significantly correlated with panicle exertion rate and outcrossing rate, indicating that parental lines with good GCA can also be economically producible. However, the duration of stigma receptivity had a very weak relationship with other floral traits except with duration of floral opening wherein a negative significant relationship was observed, indicating that as the duration of floral opening is prolonged, stigma receptivity declines, which is understandable since the stigma is exposed for a longer time, hence, the higher chances to dry up and become non-viable.

\section{Conclusion}

Based on the results, the combining ability test is a practical effective approach to identify parental lines with a high potential for the development and utilization of promising hybrid rice varieties. Likewise, there are floral traits that can determine the seed producibility of parental lines such as duration of floral opening and panicle exertion rate. Since these two traits are found to be highly associated with outcrossing ability, they can be used as selection criteria not only for identifying economically usable CMS lines but also for breeding new hybrid rice varieties.

\footnotetext{
Acknowledgements

The funding support from the Isabela State University, Echague, Isabela is hereby acknowledged. The invaluable help made by Angelito G. Galang in the
} statistical analysis of data collected from the study is also acknowledged.

\section{Authors' contributions}

All the co-authors reviewed and made corrections, if any, to the manuscript. All authors read and approved the final manuscript.

\section{Funding}

With funding support from Isabela State University, Echague, Isabela Philippines for the preparation and printing of the manuscript.

\section{Availability of data and materials}

All data generated or analyzed during this study are included in this published article [and its additional information files].

\section{Declarations}

Ethics approval and consent to participate Not applicable.

Consent for publication

All the authors gave full support and consent to the publication of this study.

Competing interests

The authors declare that they have no competing interests. 


\section{Author details}

${ }^{1}$ Isabela State University, Echague, Isabela, Philippines. ${ }^{2}$ Central Luzon State University, Science City of Muñoz, Nueva Ecija, Philippines. ${ }^{3}$ Philippine Rice

Research Institute, Maligaya, Science City of Muñoz, Nueva Ecija, Philippines.

Received: 6 February 2021 Accepted: 21 September 2021

Published online: 07 October 2021

\section{References}

Abesekara SW, Abesiriwardana D, Dehideniya E. Characteristics associated with out-crossing rate of cytoplasmic male sterile (CMS) lines in rice under local condition. Ann Sri Lanka Dept Agric. 2003;5:1-6.

Alam A, Sarker U, Mian Md. Line X tester analysis in hybrid rice (Oryza sativa L.). Ann Bangladeshagric. 2007;11:37-44.

Anand GA, Amirthadevarathinam A, Rogbell JE. Combining ability and heterosis for cold tolerance in rice. In: Agril. College and Res. Ins. Madurai 625. Tamil Nadu, India; 1999

Azmath S, Anbanandan V, Thirumalai R. Genetic effects and combining ability for yield and its components in rice (Oryza sativa L.) using line $\times$ tester; 2018

Chen H, Jiang S, Zheng J. Lin Y (2013) Improving panicle exsertion of rice cytoplasmic male sterile line by combination of artificial microRNA and artificial target mimic. Plant Biotechnol J. 2013;11:336-43.

El-Namaky R. The genetic variability of floral and agronomic characteristics of newly-bred cytoplasmic male sterile rice. Agriculture. 2018;2018(8):6.

FAO. A regional strategy for sustainable hybrid rice development in Asia; 2014. http://www.fao.org/faostat. Accessed 5 July 2020.

Fasahat P, Rajabi A, Mohseni Rad J, Derera J. Principles and utilization of combining ability in plant breeding. Biometr Biostat Int J. 2016:4(1):1-24.

Gramaje L, Caguiat J, Enriquez J, Cruz Q, Millas R, Carampatana J, Tabanao D. Heterosis and combining ability analysis in CMS hybrid rice. Euphytica. 2020. https://doi.org/10.1007/s10681-019-2542-y.
Gupta R, Sutradhar H, Chakrabarty S, Ansari W, Singh Y. Stigmatic receptivity determines the seed set in Indian mustard, rice and wheat crops. Commun Integr Biol. 2014. https://doi.org/10.1080/19420889.2015.1042630.

Hossain M, Mian M, Rasul MG, Jamil Hasan MJ, Kulsum U, Karim A. Genetic variability in floral traits of CMS lines and their relationship with outcrossing in rice. Trop Agric Dev. 2016;60:236-41.

https://ricepedia.org/challenges/food-security. 2018.

Lin SC, Yuan LP. Hybrid rice breeding in China. In: Innovative approaches to rice breeding. Manila: International Rice Research Institute; 1980. p. $35-51$.

Perraju P, Sharma MP. Combining ability studies in rice. Oryza. 1999;36(3):248-9.

Rashid M, Ali Cheema A, Ashraf M. Line x tester analysis in basmati rice. Pak J Bot. 2007:39(6):2035-42.

Shailaja H, Shankar GS. Outcrossing on male sterile plants of rice. Mysore J Agri Sci. 1987;21(2):158-60.

Singh R. Hybrid seed production mechanisms in rice (Oryza sativa L). J Biotechnol Crop Sci. 2012;1(1):4-32.

Singh R, Sahoo SK. Artificial and natural parameters influencing outcrossing of cyto-sterile lines in rice. Department of Genetics and Plant Breeding, Institute of Agricultural Sciences, B.H.U., Varanasi -221; 1996

Virmani SS. Heterosis and hybrid rice breeding. Los Baños: International Rice Research Institute; 1994

Virmani SS. Hybrid Rice. Adv Agron. 1996;57:328-462.

Virmani SS, Kumar I. Development and use of hybrid rice technology to increase rice productivity in the tropics. Int Rice Res Notes. 2004;29:10-9.

Yadav LS, Maurya DM, Giri SP, Singh SBA. Combining ability analysis for yield and its components in hybrid rice. Oryza. 1999;36(3):208-10.

Yuan LP. A concise course in hybrid rice. Hunan: Hunan Technol Press China: 1985. p. 168.

\section{Publisher's Note}

Springer Nature remains neutral with regard to jurisdictional claims in published maps and institutional affiliations.
Ready to submit your research? Choose BMC and benefit from:

- fast, convenient online submission

- thorough peer review by experienced researchers in your field

- rapid publication on acceptance

- support for research data, including large and complex data types

- gold Open Access which fosters wider collaboration and increased citations

- maximum visibility for your research: over $100 \mathrm{M}$ website views per year

At $\mathrm{BMC}$, research is always in progress.

Learn more biomedcentral.com/submissions 